estimations must be corrected for temperature. There is no evidence that the routine use of intravenous fluids, steroids, liothyronine, or vasoactive drugs is helpful. Nevertheless, because hypothermic patients tend to develop lung infections after rewarming, there may be a case for giving a prophylactic loading dose of a broad-spectrum antibiotic at once, but then not again until the temperature rises above $32^{\circ} \mathrm{C}$.

The mortality rates using this kind of regimen in the largest series are still about $50 \%,{ }^{19} 22$ but many of the elderly patients die not from hypothermia but from the illness that precipitated it. $^{19}$

${ }^{1}$ Lancet, 1978, 1, 701.

2 Kvittingen, T D, and Naess, A, British Medical fournal, 1963, 1, 1315

3 Dominguez de Villota, E M, et al, British Medical fournal, 1973, 4, 394.

4 Siebke, H, et al, Lancet, 1975, 1, 1275.

5 Trethewie, E R, Lancet, 1975, 2, 76.

6 Theilade, D, Anaesthesia, 1977, 32, 889.

${ }^{7}$ Bristow, G L, et al, Canadian Medical Association fournal, 1977, 117, 247.

${ }^{8}$ Keatinge, W R, Practitioner, 1977, 219, 183.

8 Lancet, 1978, 1, 251

10 Marcus, P, Aviation, Space, and Environmental Medicine, 1978, 49, 692.

11 Arnold, J W, and Eichenberger, C M, fournal of the American College of Emergency Physicians, 1975, 4, 438.

12 Johnson, L A, Fournal of the American College of Emergency Physicians, 1977, 6, 556.

13 Pickering, B G, Bristow, G K, and Craig, D B, Anaesthesia and Analgesia, $1977,56,574$.

14 Soung, L S, et al, Canadian Medical Association fournal, 1977, 117, 1415.

15 Stine, R J, Fournal of the American College of Emergency Physicians, 1977, 6, 413.

16 Ledingham, I McA, and Mone, J G, Lancet, 1978, 1, 391.

17 Linton, A L, and Ledingham, I McA, Lancet, 1966, 1, 24

18 Wickstrom, P, et al, American fournal of Surgery, 1976, 131, 622.

19 Maclean, D, and Emslie-Smith, D, Accidental Hypothermia. Oxford, Blackwell, 1977.

${ }^{20}$ Harari, A, et al, European fournal of Intensive Care Medicine, 1975, 1, 65.

21 Nicolas, F, et al, Anesthésie, Analgésie, Réanimation, 1974, 31, 485.

${ }^{22}$ Gregory, R T, and Doolittle, W H, Alaska Medicine, 1973, 15, 48.

\section{Which birth weight standards?}

Babies of low birth weight have always been recognised as being at special risk, not only of dying but of sustaining longterm physical and neuropsychological impairment. The proportion of babies born weighing $2500 \mathrm{~g}\left(5 \frac{1}{2} \mathrm{lb}\right)$ or less was long regarded as a good measure both of public health and of the quality of maternity services and provided a highly effective statistical basis for much of the early epidemiological study of childbearing. But this simple device was criticised on two grounds: firstly, some communities seem to have relatively low birth weight babies and a "prematurity rate" based on a fixed standard of $2500 \mathrm{~g}$ gives a misleadingly pessimistic view of the state of their public health; and, secondly, a low birth weight can indicate not only a shorter period of gestation but impaired intrauterine growth, two circumstances likely to have both different causes and different prognoses.

The publication of fetal growth standards giving distributions of birth weight at each gestational age, first by Lubchenco et $a l^{1}$ in 1963 and subsequently by many others, enabled paediatricians to break away from the ambiguities of an unqualified birth weight standard and has fuelled a great deal of clinical research. In 1970 a European working party ${ }^{2}$ advised that "the usefulness of birth weight is much increased by relating it to the gestational age and comparing the results with ... a percentile chart relating birth weight to gestational age, preferably sex-specific and based upon the population from which the clinical material is drawn...."
In applying this advice a major problem arises where the population is grossly heterogeneous, and many communities in Britain now contain a rich ethnic mixture. In these circumstances a single fetal growth standard is inappropriate. In particular, babies of Indian extraction are likely to be much $\stackrel{.}{.}$ smaller than those of European or African stock, for there $\vec{\equiv}$ appears to be a real ethnic difference in fetal growth even allowing for the small size of the mothers. ${ }^{3}$

The publication of birth weight standards from a mixed $\frac{\bar{\sigma}}{\bar{D}}$ community in the London Borough of Brent ${ }^{4}$ is therefore $\widehat{\varnothing}$ timely. The data, based on 1723 births, showed that Indian babies weigh about $300 \mathrm{~g}$ less than the white European babies with West Indians in between. Compared with the widely used $\stackrel{.}{.}$ standards based on the homogeneous population of Aberdeen ${ }^{5} \overrightarrow{\vec{\omega}}$ some $80 \%$ of Indian babies fell below the 50 th centile and $\stackrel{\circ}{\circ}$ $25 \%$ below the 10 th centile. When a correction was made for $\frac{5}{3}$ maternal size the Indian and West Indian infants came iv together to lie some $190 \mathrm{~g}$ below the white babies at each gestational age.

Welcome though these data are, a note of caution is needed, $\vec{\omega}$ because in interpreting weight-for-gestation standards and $\stackrel{\infty}{\oplus}$ their clinical application there is an uncertain concept recently ì discussed by Thomson. ${ }^{6}$ Accepting a different standard for 윽 infants of Indian origin implies the assumption that the lower $\vec{\infty}$ $10 \%$ of these infants, by that standard, have been exposed to a $Z$ degree of intrauterine growth retardation equivalent to the lower $10 \%$ of white infants by their standard, but, as Thomson $\frac{\Phi}{3}$ said, ". . . it should not be assumed without actual demonstration that this implies equal degrees of liability to neonatal $\vec{\oplus}$ or subsequent handicaps."

Conversely, an Indian baby of $2500 \mathrm{~g}$ at 40 weeks-even though it may be above the 10th centile for Indians-may be just as much at risk as a white baby of $2500 \mathrm{~g}$, which at term is well below the 10th centile. We need more information, and the data from the Brent group and others need to be expanded $\frac{\Phi}{\square}$ so that appropriate birth weight standards can be established $\stackrel{\square}{\vec{F}}$ for all the different groups in our heterogeneous population.

1 Lubchenco, L O, et al, Pediatrics, 1963, 32, 793.

2 Neligan, G A, et al, in Proceedings of the 2 nd European Congress of Perinatal Medicine, ed P J Huntingford. London 1970. Basle, Karger, 1971.

${ }^{3}$ Hytten, F E, and Leitch, I, Physiology of Human Pregnancy, 2nd edn. Oxford, Blackwell, 1971.

4 Grundy, M F B, Hood, J, and Newman, G B, British fournal of Obstetrics and Gynaecology, 1978, 85, 481.

5 Thomson, A M, Billewicz, W Z, and Hytten, F E, fournal of Obstetrics and 8 Gynaecology of the British Commonwealth, 1968, 75, 903.

6 Thomson, A M, and Billewicz, W Z, in The Biology of Human Fetal 0 Growth, eds D F Roberts and A M Thomson. London, Taylor and Francis, 1976.

\section{Don't forget Wilson's disease}

Though originally described as a neurological disorder with 0 associated cirrhosis, ${ }^{1}$ we now recognise hepatolenticular degeneration (Wilson's disease) as a copper storage disorder ${ }^{2}$ in $\stackrel{\odot}{\stackrel{\oplus}{\oplus}}$ which other tissues become affected as the excess copper is $\stackrel{\mathbb{Q}}{\Omega}$ released from the liver. ${ }^{3}$ Indeed, in those patients whose symptoms develop in the first two decades of life the early 8 features are mostly due to hepatic dysfunction.

Excluding the diagnosis of Wilson's disease is important in patients with liver disease, for the prognosis has improved $\rightleftharpoons$ enormously since Walsh introduced treatment with D-penicillamine. ${ }^{4}$ Adequate treatment of asymptomatic 
patients ${ }^{5}$ completely prevents the development of clinical disease. Furthermore, the results of treatment in patients with overt disease are also impressive: in most cases symptoms and signs regress and the prospects of survival are good, whereas formerly virtually all patients died. Strickland et $a l^{6}$ examined the prognosis in 142 patients with Wilson's disease, including 88 who had been treated with penicillamine for up to 16 years. Of 36 symptomatic patients who had not been treated, all but one were dead; while 31 of the 35 symptomatic patients being treated with penicillamine remained alive, including 22 who had had penicillamine for two years or more; only six of these had residual symptoms. The overall experience suggests that the disease is completely and permanently controlled in patients who are lucky enough to be diagnosed and treated at an early stage. ${ }^{78}$

Other patients do not fare as well-those with established cirrhosis and portal hypertension and renal tubular damage. ${ }^{6}$ Some patients present with fulminant hepatitis, ${ }^{9}$ often associated with acute intravascular haemolysis, ${ }^{10}$ when the only hope may be peritoneal dialysis. ${ }^{11}$ The rare patients who cannot tolerate penicillamine ${ }^{1213}$ may be treated with the chelation agent triethylene tetramine hydrochloride. ${ }^{14}$ Hepatic transplantation is one radical alternative in patients with advanced disease; it may even correct the underlying metabolic abnormality. ${ }^{15}$

The hepatic manifestations of Wilson's disease vary from asymptomatic cirrhosis to fulminant hepatic failure. Doctors must maintain a high index of suspicion, especially in young patients, though the middle aged may also present with hepatic disease. ${ }^{16}$ This need for awareness is especially true of chronic active hepatitis, which is thought to be due to copper overload in as many as $5 \%$ of cases. ${ }^{17}$ Scott et al ${ }^{18}$ from the Royal Free Hospital recently published a series of such patients in whom the outcome was disappointingly poor even with penicillamine treatment: over half of them died within two years of presentation. They suggested that diagnosis may frequently be delayed beyond the point of optimal response to treatment in this syndrome, which is clinically and biochemically indistinguishable from other types of chronic active hepatitis unless copper metabolism is studied. Once suspected, the diagnosis may be established without undue difficulty on the basis of raised copper concentrations in the liver and in the urine. Scott et al found that these were raised in all cases, though the serum caeruloplasmin concentration was normal in three patients; the results of rubeanic acid staining of liver tissue for copper proved unreliable.

Clearly the best use of the lifesaving potential of penicillamine treatment in Wilson's disease comes from early diagnosis. Suitable diagnostic procedures have been reviewed recently by Sternlieb, ${ }^{19}$ who argued that-despite the many reported pitfalls-most patients are diagnosed correctly with standard investigations and that few need such refinements as radiocopper loading tests. Nevertheless, the clinician's most potent ally remains an awareness of the possibility of Wilson's disease in the differential diagnosis.

1 Wilson, S A K, Brain, 1912, 34, 295.

2 Cumings, J N, Brain, 1948, 71, 410

${ }^{3}$ Sternlieb, I, and Scheinberg, I $\mathrm{H}$, in The Liver and Its Diseases, eds $\mathrm{F}$ Schaffner, S Sherlock, S and C M Leevy, p 328. New York, Intercontinental Book Corporation, 1974.

4 Walshe, J M, American fournal of Medicine, 1956, 21, 487.

5 Sternlieb, I, and Scheinberg, I H, New England fournal of Medicine, 1968, 278, 352.

6 Strickland, G T, et al, Quarterly fournal of Medicine, 1973, 42, 619.

? Deiss, A, et al, Annals of Internal Medicine, 1971, 75, 57.

${ }^{8}$ Arima, M, et al, European fournal of Pediatrics, 1977, 126, 147.
9 Adler, R, et al, American fournal of Diseases of Children, 1977, 131, 870. Roche-Sicot, J, and Benhamou, J-P, Annals of Internal Medicine, 1977, $86,301$.

11 Hamlyn, A N, et al, British Medical fournal, 1977, 2, 660.

12 Walshe, J M, Postgraduate Medical fournal, 1968, suppl, p 6.

${ }^{13}$ Scheinberg, I H, Postgraduate Medical fournal, 1968, suppl, p 11.

14 Walshe, J M, Quarterly fournal of Medicine, 1973, 42, 441.

15 Beart, R W, et al, Lancet, 1975, 2, 176.

${ }^{16}$ Fitzgerald, M A, et al, Mayo Clinic Proceedings, 1975, 50, 438.

17 Sternlieb, I, and Scheinberg, I H, Annals of Internal Medicine, 1972 76, 59 .

18 Scott, J, et al, Gastroenterology, 1978, 74, 645.

19 Sternlieb, I, Gastroenterology, 1978, 74, 787.

\section{Storage and cooking of poultry}

As Christmas approaches, it is safe to predict that there will follow the usual reports of food poisoning in people who have eaten turkey, chicken, duck, or goose. The amount of distress and trouble caused by such food poisoning is well known. Not infrequently cold chicken is the vehicle of infection. The bird is often one that has come from a deep freeze and has been thawed for only an hour or two before being roasted for too short a time at too low a temperature to guarantee that even vegetative bacteria will be killed. Inadequate heating is often followed by too slow cooling, and, worst of all, the chicken may simply be left overnight at room temperature. In this way a temperature favourable for bacterial growth is maintained for enough hours to ensure that the carcase is heavily colonised by the rapid growth of any salmonellas not killed by the cooking.

As a result a large proportion of those who have eaten the chicken are shortly stricken with severe abdominal pains, diarrhoea, vomiting, and possibly a generalised infection with fever. Food-handlers may be laid off work for many weeks if -as often-they carry the salmonella that has infected them from the chicken. The inference is not hard to draw and the lesson to be learned should be: let your hot be hot and your cold be cold. Such incidents, causing much distress and an incredible amount of work to all concerned in their investigation and management, are not properly described as "accidents" because they are readily preventable by applying the elementary rules of kitchen hygiene.

In present conditions, it is well to assume that any chicken, goose, duck, or turkey carcase may be contaminated with food-poisoning salmonellas or spoilage bacteria. The probability of such contamination is much higher in deep-freeze poultry than in unfrozen birds. One day, perhaps, salmonella infection of poultry may be cut off or much reduced by measures taken in breeding establishments and processing plants and in animal-feed production; but this remains only a future hope. So it is essential to make sure that frozen poultry is well thawed, properly cooked, and stored in the cold if not to be eaten at once after cooking. This advice can be specified in some detail. Thawing a deep-freeze carcase should mean leaving it for a full 24 hours at room temperature; because, if a bird is only partially thawed, the penetration of heat will not be enough to destroy even vegetative bacteria in the deeper parts of the bird. Cooking must be done in a pre-heated oven and the time and temperature requirement is about $180-200^{\circ} \mathrm{C}$ for $20-30$ minutes per pound plus 30 minutes extra. The higher times and temperatures are for larger birds-say, over $10 \mathrm{lb}$-and the weight of any stuffing must be included in the calculation. 